This item was submitted to Loughborough's Research Repository by the author.

Items in Figshare are protected by copyright, with all rights reserved, unless otherwise indicated.

\title{
Does tax competition make mobile firms more footloose?
}

PLEASE CITE THE PUBLISHED VERSION

https://doi.org/10.1111/caje.12375

PUBLISHER

(c) Canadian Economics Association. Published by Wiley

VERSION

AM (Accepted Manuscript)

\section{PUBLISHER STATEMENT}

This is the peer reviewed version of the following article: FERRETT, B.E., HOEFELE, A. and WOOTON, I., 2018. Does tax competition make mobile firms more footloose?. Canadian Journal of Economics / Revue Canadienne d'Économique, 52 (1), pp.379-402, which has been published in final form at https://doi.org/10.1111/caje.12375. This article may be used for non-commercial purposes in accordance with Wiley Terms and Conditions for Use of Self-Archived Versions.

\section{LICENCE}

CC BY-NC-ND 4.0

\section{REPOSITORY RECORD}

Ferrett, Ben, Andreas Hoefele, and lan Wooton. 2019. "Does Tax Competition Make Mobile Firms More Footloose?". Loughborough University. https://hdl.handle.net/2134/32567. 


\title{
Does tax competition make mobile firms more footloose?
}

\author{
Ben Ferrett* \\ Loughborough University \\ Andreas Hoefele \\ Competition and Markets Authority \\ Ian Wooton \\ University of Strathclyde, CEPR and CESifo
}

MARCH 2018

\begin{abstract}
We examine a two-period regional model with evolving economic geography, potentially creating incentives for firm relocation between periods. We argue that tax competition makes firms more footloose, but that this increases efficiency relative to the laissez-faire outcome. We establish that: (1) tax competition leads to efficient investment outcomes; and (2) firm mobility is greater with tax competition than with a laissez-faire regime. When relocation is costly, there can be too little mobility over time, as firms do not take into account the impact of FDI on social welfare in each country. With lump-sum taxes or transfers, firms capture these benefits and internalize them, such that tax competition leads to the efficient outcomes. When more time periods are examined, tax competition induces firm relocation sooner than in its absence.
\end{abstract}

Keywords: FDI, dynamic tax competition, geographical change, efficiency

JEL Classification: F23, H25, R38

\footnotetext{
* Corresponding author: email b.e.ferrett@lboro.ac.uk. We are grateful for comments received at presentations at ETSG conferences, seminars at ETH Zurich, Florida State University, Loughborough University, University of Munich, NUI Maynooth, Peking University, Tokuku University, University College Dublin, the Mannheim workshop on Taxing Multinational Firms, the Midwest Trade Meeting at IUPUI, and the APTS conference in Canberra. In particular, we would like to thank Arijit Mukherjee, Johannes Becker and Tuvana Pastine for their discussion and suggestions.
} 


\section{Introduction}

National governments often give significant tax and other incentives to foreign-owned firms in order to induce them to establish local production facilities, yet the lifespan of these subsidised plants is often short. Many firms subsequently move to new locations that have become more profitable than their initially chosen production sites. This reflects the fact that the "geographic advantage" one location enjoys relative to another is transient, changing over time, such that firms eventually choose to relocate, despite having been given inducements to invest. For example, in 2008, the German public was outraged and demanded the repayment of public subsidies when Nokia announced the relocation of its handset production from North-Rhine Westphalia to Romania, a little over a year after the end of a sizeable subsidy agreement between the firm and German local government. ${ }^{1}$ Moreover, it is often asserted that subsidies play a significant role in such plant relocations, and there is some case-study evidence to support this view. For example, in December 2010, the Financial Times introduced the report of its wide-ranging investigation into the links between international plant relocations and $\mathrm{EU}$ subsidies by stating that "(m)illions of euros in EU subsidies have been allocated to companies relocating factories from western to eastern Europe despite specific rules designed to prevent taxpayer subsidies from going to corporations moving plants in search of cheaper labour."”2

This paper investigates the effect on observed firm mobility of governments making competing offers to attract and retain foreign direct investment (FDI) as the pattern of geographic advantage evolves over time. In particular, we wish to determine whether any

\footnotetext{
1 In January 2008, Nokia announced the closure of its plant in Bochum, with the loss of 2300 jobs, and the relocation of production to a subsidised site near the city of Cluj in Romania. Ironically, Nokia subsequently announced in September 2011 that the Romanian factory was itself to be shut down and production shifted to China.

See http://news.bbc.co.uk/1/hi/business/7232367.stm and http://www.bbc.co.uk/news/world-europe-16290078. A further, much-cited example of a short-lived, subsidised plant is the Siemens microchip factory in the northeast of England, which operated for only 18 months in the late 1990s; see http://news.bbc.co.uk/1/hi/business/332560.stm.

2 See http://www.ft.com/cms/s/0/74ab02a6-fd85-11df-a049-00144feab49a.html?siteedition=uk\#axzz48oi3kEfr.
} 
changes in industrial location associated with international tax/subsidy competition for FDI are beneficial to society. Beyond this, we wish to determine whether such fiscal inducements can make firms more "footloose" than they would have been in the absence of such offers.

At the outset of our research, we anticipated that financial inducements offered for FDI would reduce the likelihood of firm relocation in response to asymmetric growth in national market sizes. Our intuition suggested that, if the governments could anticipate future geographical developments and build them into their initial fiscal offers, there would be a more muted reaction to the unfolding of geography over time than would arise in the absence of international bidding for FDI. We shall demonstrate that this intuition is incorrect and attempt to provide an intuitively appealing explanation of the correct outcome.

We consider the FDI decisions of a multinational enterprise (MNE) in a multi-period model of production, trade and consumption in a region composed of two countries with an evolving pattern of geographic advantage that might arise from, inter alia, different national rates of growth in population and market size, changing production costs, or improvements in local infrastructure. The firm seeks to maximise the present value of its after-tax profits, which we assume are repatriated to the MNE's foreign owners. ${ }^{3}$

With the existence of sunk set-up costs for the firm's operations, such as building the plant or searching for the optimal location within a country, relocating production is more costly than staying in the initial location. This might create inertia on the part of the firm, such that it chooses to remain in one place despite the existing host country having become the lessprofitable location. Alternatively, if a nation is anticipated to develop a strong geographic advantage in the future, there is the potential that it will attract the firm immediately, despite being the less-profitable location when the FDI takes place.

\footnotetext{
3 The profits of the firm therefore do not contribute to the welfare of citizens of the countries competing to attract the FDI. See Ferrett and Wooton (2010b) for a discussion of the implications of domestic ownership of (parts of) the firm.
} 
Our model has two active governments, that prefer local production to imports and consequently are prepared to make offers of lump-sum taxes/subsidies in an attempt to attract the FDI of the MNE. We wish to examine how government policies may encourage or hinder relocation of FDI in a changing economic environment. Initially, we consider a setting with two time periods, in each of which the two governments can make offers to the firm. The firm can stay in its original location or choose to relocate at the beginning of the second period. Later in the paper, we extend our time horizon with asymmetric country growth over many periods. In this latter setting, we ask whether government competition induces the firm to relocate sooner (or delay its decision) compared to the timing of its choice in the absence of the competition between countries.

The starting point of our analysis is the model of Haufler and Wooton (1999), who examine the tax competition for FDI between two asymmetric countries. Their analysis is "static", in the sense that it focuses on cases where the underlying geography is fixed and the firm/government interaction is one-shot. Thus, their model explains the firm's initial choice of plant location, but can say nothing about possible plant relocation over time. The contribution of our paper is in extending the time horizon of the Haufler/Wooton framework to allow for repeated interactions between governments and the firm. As such, this paper adds to a relatively small literature on tax competition over time.

As our benchmark, we derive the equilibrium location decisions of the firm over time when the governments do not bid to attract its FDI and, consequently, geographic advantage is the sole determinant of location. We call this our "laissez-faire" (LF) case and we shall contrast it with our case of "tax competition" (TC), where countries bid in each period to attract or retain the FDI in order to maximise their domestic welfare. We show that, as geographic advantage evolves, the firm under laissez faire will choose one country or the other as its permanent location or may decide to relocate after the first period. We compare this equilibrium 
with the "efficient" outcome, where the firm's location in each period is chosen to maximise the present value of world welfare. We then complete the analysis by showing that tax competition yields the efficient outcome.

We illustrate our result using an example where the changing economic geography of the region results from differential growth in national market size. This allows us to show that tax competition results in the firm being "more likely" to relocate production between periods, in that there is a broader part of the parameter space under which the firm will relocate under tax competition than with laissez faire. Under tax competition, the host governments absorb some of the firm's relocation costs in their tax/subsidy offers, resulting in the greater propensity for relocation of production.

\subsection{Related literature}

In our model, geographical change is necessary to explain plant relocations over time. In contrast, adopting fixed geography, King et al. $(1992,1993)$ account for the relocation of a single firm's plant in a closely-related two-period model of international competition on the basis of ex ante uncertainty and ex post disappointment. In their approach, the firm does not know the countries' characteristics with certainty before choosing its initial location, and it might move away after investing if conditions turn out to be sufficiently worse than expected.

Unlike us, King et al. downplay relocation issues and concentrate on the time profile of taxes paid in a given location. ${ }^{4}$ The sunk nature of FDI limits mobility between periods and allows the first-period host nation to extract rents from the firm in the second period. Anticipating these future tax payments, the firm receives a subsidy in the first period.

In contrast, we focus on how the sunk cost of FDI allows the firm to use its choice of initial location strategically in order to reduce its future tax burden. The host in the second period will offer a lower tax if it attracts new FDI through relocation between periods than if it

\footnotetext{
${ }^{4}$ Furthermore, they do not analyse the comparison between laissez faire and tax competition.
} 
already hosted the production facility from the first period. The deterministic (as opposed to probabilistic) treatment of geography in our model facilitates a transparent analysis of the incentives that relocation opportunities create for the firm. Moreover, given the amount of effort that firms and their agents typically put into researching alternative locations, the preinvestment ignorance assumed by King et al. may seem implausible. In contrast to theirs, our model can explain plant relocations in the absence of uncertainty or surprises and we view this as a distinctive contribution.

A second closely related contribution is Konrad and Kovenock (2009), who study tax competition over time in the context of fixed geography. In their model, firms arrive and invest sequentially in a flow, each living for two periods and unable to relocate, whereas our single firm can move as conditions change. If there is no means of discriminating between firms in tax setting, a country thus faces a trade-off between imposing a high tax on existing, immobile capital and setting a low tax in order to attract new FDI. Our paper builds on the insight, that the sunk nature of FDI implies higher taxes on established than on new investment, by allowing our firm to respond strategically through the possibility of relocation.

Two other papers that are relevant but less closely related to ours are Haaland, Wooton and Faggio (2003) and Besley and Seabright (1999). In line with our framework, both of these models have a time dimension and allow governments to offer FDI subsidies. Unlike our model, neither allows for firm relocation in the light of changing economic geography. In Haaland et al. a single MNE compares the national set-up and closure costs of investment in order to decide upon the irreversible location for its production facility that has an uncertain lifespan. Besley and Seabright analyse a policy competition model with two host countries and two investing firms. The two firms arrive, receive bids, and make their irreversible location decisions in sequence. It is shown that this sequential-auction structure can result in inefficient outcomes. For our present purposes, however, a key observation is that neither paper allows 
for future relocation away from a firm's initially chosen site, which is a mechanism that is central to our model.

The remainder of the paper is organised as follows. The next section describes our model. Section 3 then considers the outcome of firm location under laissez faire. We then examine the impact of tax competition in Section 4 and establish that it results in global efficiency. In order to answer the question asked in the title of this paper, we adopt a specific example of our model in Section 5. In this setting, we show that the firm is "more footloose" under tax competition than laissez faire. Section 6 considers two extensions to our analysis, introducing commitment in tax-setting and moving from two periods to an infinite time horizon. Section 7 offers a summary and conclusions.

\section{The Model}

Our model comprises a region composed of two countries, a single firm, and two periods, labelled 1 and 2. The countries, denoted $A$ and $B$, constitute a regional market for the firm's product and compete against each other to attract inward FDI from the firm. We assume that the region is surrounded by prohibitive trade barriers. This means that, if the firm wishes to sell

to consumers in the region, then it must invest and produce in either $A$ or $B$. The fixed costs of production ensure that the firm will operate only one plant at any point in time, with exports within the region being subject to a (non-prohibitive) trade cost. Our key modelling innovation is that the geography of the region changes over time, such that the preferred location (for the firm or the governments) may change from one period to the next.

In our benchmark case of laissez faire (LF), governments do not try to influence the location of the firm's investment. But, if we assume that inward FDI creates a welfare gain for the host country, relative to the benefits of importing the good from the other country in the region, the national governments will seek to maximise the welfare of their residents by 
engaging in tax competition (TC) to attract the FDI. The firm's owners reside outside the region and, therefore, their welfare is ignored by both countries.

The firm chooses its actions in order to maximise the present discounted value of its net (after-tax) profits. Let $\pi_{i t}$ denote the pre-tax profits that accrue to the firm from locating in country $i$ in period $t$, where $i \in\{A, B\}$ and $t \in\{1,2\}$. We define $\Pi_{t} \equiv \pi_{B t}-\pi_{A t}$ to be the profit gain from locating in country $B$ as opposed to country $A$. We consequently say that if $\Pi_{t}>0$ then country $B$ has a "geographic advantage" over country $A$ in period $t$ with respect to its ability to attract the FDI.

The firm may relocate its production between the periods. Building a plant in either country entails a sunk, capital cost of $F$ for the firm. We assume for simplicity that, once a plant has been established, its capital does not depreciate over time. ${ }^{5}$ There is a per-period, fixed $\operatorname{cost} C$ of operating a plant that is sufficiently large such that the firm will only ever operate one plant, even if it has built one in each country. ${ }^{6}$ The discount factor $\delta \in[0,1]$ is common to both host countries and the firm. If $\delta=1$ then equal weights are placed on the payoffs in the two periods, whereas $\delta=0$ means complete myopia. While our initial analysis assumes two periods, we shall eventually extend this to many periods.

\subsection{Timing of the game}

The periods are separated by changes in the firm's profitability arising from its location choice. In each period, the firm chooses the location of its plant and its production level. In the case of laissez faire, LF, where the governments make no direct attempts to influence the firm's choice of location, the prime influence on the firm will be the relative geographic advantage of one location to the other and how this evolves. Under tax competition, TC, the firm and both countries aim to maximise the present discounted values (PDV) of their payoffs (post-tax

\footnotetext{
5 We consider the effects of allowing for depreciation in Section 3.2, below.

6 This cost $C$ plays a background role in our model, in that it exists only to generate sufficiently large increasing returns to scale in production, and it plays no role otherwise.
} 
profits for the firm and social welfare in each of the two countries), where the countries compete for the FDI by bidding in two, sequential auctions. Table 1 summarises the sequence of moves in the two cases.

\section{TABLE 1 ABOUT HERE}

Under tax competition, the potential host countries announce their offers simultaneously in each period in a first-price, sealed-bid auction. These offers are irreversible within a period but governments may make different offers in each of the two periods. ${ }^{7} \mathrm{We}$ adopt the standard assumption that a country never bids more it stands to gain from attracting the inward FDI. The countries' reservation bids are therefore given by their valuations. ${ }^{8} \mathrm{We}$ show in Section 4, below, that this yields a unique bidding equilibrium, where the losing country bids exactly its valuation while the winning country makes a bid that is just sufficient to attract the FDI. ${ }^{9}$

Our game is one of complete information, and we assume that the change in the economic geography between periods 1 and 2 is fully anticipated. Our solution concept is the subgame-perfect Nash equilibrium in pure strategies and we shall compare the firm's equilibrium location choices under tax competition and laissez faire.

\section{The firm's location choice under laissez faire}

We start by focusing on the FDI decision of the firm in the absence of any government intervention. Under laissez faire, the governments refrain from setting taxes or subsidies in

\footnotetext{
7 In Section 6.1, we consider what happens if the host countries and the firm can make binding commitments at the start of period 1 .

8 This assumption can be justified by noting that all bids above a country's valuation are weakly dominated by a bid equal to its valuation. Thus, for example, the possibility that its rival for the FDI might have a "trembling hand" would deter a country from bidding above its valuation. See Ferrett and Wooton (2010b) for a detailed discussion of equilibrium behaviour within the auction structure that we adopt. Furosawa, Hori and Wooton (2015) consider the differences between first-price and English auctions for a firm under complete and incomplete information.

9 If the firm's pre-tax profits are greater in the winning country, then that country will bid less than the losing country in equilibrium.
} 
either period. The firm's choice of location is therefore based upon a comparison of the profits arising from production in the alternative locations in each period together with any required relocation cost. The location pattern that we derive in this case becomes the benchmark for our later analysis of the implications of governments bidding to attract the FDI under tax competition.

Figure 1 depicts the firm's equilibrium locations under laissez faire in $\left(\Pi_{1}, \Pi_{2}\right)$ space. The area labelled $A B$ corresponds to the firm adopting the location profile $A B$, where the firm chooses to produce in $A$ in period 1 and in $B$ in period 2. Similarly, zones $B B, B A$, and $A A$ in the diagram correspond to their respective location profiles. Dashed lines mark the boundaries between the location profiles under laissez faire and are labelled "LF".

\section{FIGURE 1 ABOUT HERE}

In order to interpret Figure 1, we begin by thinking about the firm's location choice in period 2, which depends on $\Pi_{2}, B$ 's geographic advantage in that period. $B$ will always be chosen in period 2 if its geographic advantage is sufficiently large, such that $\Pi_{2}>F$, regardless of the firm's location in period $1 .{ }^{10}$ In these circumstances, even if the firm had located in A in period 1, it would choose to move to $B$ in the next period, as $B$ 's geographic advantage in period 2 is sufficiently large to compensate the firm for the costs of relocation and building a new plant. Likewise, if the firm was already in $B$ in period 1, relocation to $A$ in period 2 would only be profitable if $\Pi_{2}<-F$, where $B$ 's geographic advantage had declined sufficiently to justify building a new plant in $A$. These two inequalities determine the positions of the two horizontal inter-regional boundaries in Figure $1 . \Pi_{2}>-F$ is less demanding than $\Pi_{2}>F$ and consequently the firm is "more likely" to choose $B$ in period 2 if it previously chose $B$ in period 1. This is because continuing to produce in $B$ does not involve a relocation cost, whereas

${ }^{10}$ Similarly, $A$ is always chosen in period 2 if $\Pi_{2}<-F$. 
moving to $B$ from $A$ does. Indeed, the firm might optimally remain in $B$ in period 2 even if $B$ loses its geographic advantage, $\Pi_{2}<0$, if the cost of relocation made such a move unprofitable.

On the basis of the above discussion, and in order to determine the firm's location profile over time, we consider the following three cases, corresponding to the strength of $B$ 's geographic advantage in period 2.

Case 1. $\Pi_{2}>F$. When $B$ has a strong geographic advantage, the firm always chooses $B$ in period 2, and thus its location profile is either $A B$ or $B B . B B$ is chosen if and only if $\Pi_{1}>-\delta F$; that is, as long as $B$ does not have a first-period geographic disadvantage that is sufficiently large to justify initial production in $A$ with subsequent relocation costs.

Case 2. $-\Pi_{2}>F$. This is the converse of Case 1 , where $B$ 's period-2 geographic disadvantage is sufficiently large that $A$ always hosts the production in period 2. Overall, $B A$ is chosen over $A A$ if and only if $\Pi_{1}>\delta F$ such that $B$ 's first-period geographic advantage is sufficient to offset the subsequent relocation cost.

Case 3. $\left|\Pi_{2}\right|<F$. This is the intermediate case where, in period 2, B's geographic advantage is such that the firm optimally chooses to remain wherever it produced in period 1. $B B$ dominates $A A$ if and only if $\Pi_{1}+\delta \Pi_{2}>0$, which arises when $B$ 's initial geographic advantage is sufficient to offset its future, discounted geographic disadvantage. This inequality then defines the negatively sloped boundary between $A A$ and $B B$ in Figure 1.

We are especially interested in the location profiles $A B$ and $B A$, as these involve relocation of production between period 1 and period 2 and would therefore provide evidence of the firm being "footloose". Proposition 1 summarises the conditions under which $A B$ and $B A$ are the equilibrium outcomes. 
Proposition 1. Under laissez faire, a forward-looking firm will only choose to switch the location of its production between periods 1 and 2 if the geographically disadvantaged country in the first period acquires a compensating geographic advantage in the second. It must also be the case that both:

(i) the geographic advantage of the host country in period 1 exceeds the PDV of building a new plant in period 2; and

(ii) the newly acquired geographic advantage of the host country in period 2 is greater than the cost of building the new plant.

In these circumstances, the firm will choose to switch locations, in order to follow geographic advantage.

Proof. The intertemporal reversal in geographic advantage establishes that relocation occurs only in quadrants 2 and 4 of Figure 1 . Part (i) refers to the vertical boundaries of $A B$ and $B A$, that require $-\Pi_{1}>\delta F$ and $\Pi_{1}>\delta F$, respectively. Part (ii) refers to the horizontal boundaries of $A B$ and $B A$, that require $\Pi_{2}>F$ and $-\Pi_{2}>F$, respectively.

The pattern of the LF thresholds in Figure 1 makes intuitive sense. For relocation to occur, there needs to be a reversal in geographic advantage that is sufficiently large to justify the building of new production facilities in the other country. We now consider two extensions to the analysis, both of which are straightforward within the context of Figure 1.

\subsection{Unanticipated change in geographic advantage}

First, suppose that the firm expects the existing geographic advantage in period 1 to persist into the future. In that case, any change in the geography between periods 1 and 2 will be unanticipated and both of the relocation regions, $A B$ and $B A$, will expand sideways. Thus, if the firm assumes that $\Pi_{2}=\Pi_{1}$ when deciding its period-1 location, it will choose $B$ initially if and only if $\Pi_{1}>0$. In other words, the $A B / B B, A A / B B$ and $A A / B A$ inter-regional boundaries 
would all coincide with the vertical line $\Pi_{1}=0 .{ }^{11}$ Consequently, relocation by the firm between periods 1 and 2 is "more likely" if the geographical change is unanticipated. When the firm knows of a future change in geographical advantage, it takes this into account in making its initial choice of location. If, however, the geographical change is unanticipated, the only opportunity for the firm to adjust is after the fact, making relocation "more likely". In Figure 1, the impact of unanticipated geographical change is identical to the behaviour of a completely myopic firm (that is, $\delta=0$ ).

\subsection{Fixed plant costs}

The presence of a one-off sunk plant cost raises the possibility that the geographically disadvantaged country might host the firm for a period (as it has the geographic advantage in the other period). Thus, the location profiles $A A$ and $B B$ are both chosen in equilibrium in parts of quadrants 2 and 4 of Figure 1. Now suppose that the plant cost $F$ were fixed rather than sunk, perhaps due to complete depreciation of the productive capital between periods, such that $F$ must be paid in both periods even if production remains in the same location. In this situation, the firm optimally chooses $B$ in period $t$ if and only if $\Pi_{t}>0$. Each of the four regions in Figure 1 would then coincide exactly with one of the quadrants. Thus the absence of a sunk cost creates separability between the periods, such that the firm's location in a given period depends only on contemporaneous geographic advantage. ${ }^{12}$

\footnotetext{
${ }^{11}$ However, the vertical positions of the flat $A B / A A$ and $B A / B B$ inter-regional boundaries do not change because when period 2 arrives, the new geography is revealed and the firm's period- 2 decision problem is then identical to that under anticipated geographical change.

${ }^{12}$ In this situation, with $F$ as a per-period fixed cost, our model follows Haufler and Wooton (1999) in finding that, in any period, the larger (geographically advantaged) country within a region always wins the FDI, under both laissez faire and tax competition.
} 


\section{The effects of tax competition}

We assume that inward FDI creates a welfare gain for the host country, relative to the benefits of importing the good from the other country in the region. This creates an incentive for the countries to bid to attract the firm's investment in both periods.

For period 1, let the social welfare of country $i$ be $H_{i 1}$ when it hosts the MNE's plant and $M_{i 1}$ when it imports the good from the other country, where $i \in\{A, B\}$. Thus, country $i$ 's welfare gain from local production in period 1 is $W_{i 1} \equiv H_{i 1}-M_{i 1}$, where we assume that this "valuation" is strictly positive, $W_{i 1}>0$.

There are many explanations as to why local production following inward FDI might be associated with higher social welfare compared to importing the products. Haufler and Wooton (1999) provide detailed microfoundations for the case where intra-regional trade is costly and production costs are identical in the two countries, such that the market price of the product is lower when it is produced locally rather than being imported from abroad. In their setting, $H_{i 1}$ and $M_{i 1}$ are the levels of consumer surplus under hosting production and importing the good, respectively. ${ }^{13}$ Additional social benefits from inward FDI have been considered in other papers. For example, there may be wage premia for domestic workers in "good" MNE jobs or the FDI may offer some relief of involuntary unemployment (e.g. Bjorvatn and Eckel, 2006; Haaparanta, 1996). Domestic firms may benefit from localised technological spillovers (e.g. Fumagalli, 2003; and Olsen and Osmundsen, 2003), while there may be a net fiscal contribution from the mobile factors associated with the inward FDI (e.g. Black and Hoyt, 1989). All that we need for our analysis is that governments value inward FDI over imports. ${ }^{14}$

\footnotetext{
13 Ferrett and Wooton (2010a) provide microfoundations for bidding motivated by such consumer-surplus considerations in the context of tax competition for two, competing firms. Janeba (1998) also studies policy competition for firms in a duopoly, but his set-up is very different from ours.

14 Ferrett and Wooton (2010b) discuss, in detail, the microfoundations of a single-period model of tax competition for a monopolist. In the interests of brevity, we refer the interested reader there and treat equilibrium levels of social welfare and profits as parameters in what follows.
} 
In period 2, a country will again benefit from being the host to the FDI as compared to importing the good, but these benefits may be tempered by what happened in the previous period. Thus, the welfare arising from continuing to host a plant in period 2 might be greater than that associated with attracting new FDI, given the potential costs of disruption and adjustment to accommodating the new production facility. Equally, it might be better never to have hosted production than to have to deal with the costs associated with the closure of a production plant. Our general formulation allows for these possibilities and we introduce notation corresponding to these potential outcomes. We use uppercase variables to denote the social welfare of country $i$ in period 2 under hosting and importing, respectively, when the MNE's location is unchanged from the previous period. Thus, $H_{i 2}$ corresponds to the welfare of country $i$ associated with retaining the production facility in period 2, while $M_{i 2}$ is the country's welfare when it continues to import the good. In contrast, when the firm relocates its production from one country to the other we use lowercase variables for social welfare. Thus country $i$ gets $h_{i 2}$ when it starts to host the firm in period 2 and receives $m_{i 2}$ if begins to import the good, having previously produced it. ${ }^{15}$ We illustrate our notation in Figure 2.

\section{FIGURE 2 ABOUT HERE}

Our set-up is sufficiently general to allow for many possibilities but the discussion, above, suggests a plausible ranking of period-2 welfare levels:

$$
H_{i 2}>h_{i 2}>M_{i 2}>m_{i 2}
$$

This ranking reflects the assumption that continuity generates benefits to national welfare such that, regardless of whether the country hosts the firm or imports the good in period 2, its social welfare is higher if its status as host or importer is maintained from the previous period. This reflects the benefits from continuity and the costs from disruption of industrial activity. An

\footnotetext{
15 Of course, the simplest case is the one where national welfare in period 2 is independent of the past location of production, that is $H_{i 2}=h_{i 2}$ and $M_{i 2}=m_{i 2}$. We make this assumption in our example in Section 5 .
} 
example of the former would be the human-capital appreciation arising through learning-bydoing that creates positive externalities for the host country, while the latter might include the adjustment costs borne by domestic factors of production from the loss of their employment resulting from the relocation of the FDI.

Consequently, in period 2 a country has two possible valuations for hosting the FDI. We let $W_{i 2} \equiv H_{i 2}-m_{i 2}$ represent country $i$ 's national welfare valuation of FDI in period 2 when it continues to host the plant, while $w_{i 2} \equiv h_{i 2}-M_{i 2}$ is country $i$ 's valuation of FDI in period 2 when it previously imported the good. As we are assuming that neither country will bid more than it stands to gain from attracting the inward FDI, then the countries' reservation bids are given by these valuations. The ranking in (1) implies that:

$$
W_{i 2}>w_{i 2}>0
$$

Expression (2) captures the idea that an existing host nation will be willing to fight harder to retain an existing plant than an otherwise identical country will be to attract new FDI.

Having established that national governments would like to attract FDI, we devote the remainder of this section to analysing the equilibrium under tax competition and to proving that the MNE's equilibrium location profile over time under tax competition is always efficient. This result will save us from having to solve the game period-by-period. Instead, we can look for efficient location outcomes in the knowledge that these will coincide with the taxcompetition equilibrium.

We consider the conditions under which $B B$ will arise in equilibrium under tax competition. It is straightforward to adjust our argument to derive the equilibrium conditions for the other three location profiles.

\subsection{BB equilibrium in period 2}

If the firm located in country $B$ in period 1 , then $B$ will retain the plant in period 2 if and only if

$$
W_{B 2}+\Pi_{2}>w_{A 2}-F
$$


The left-hand side of this inequality combines the geographic advantage to the firm of remaining in country $B$ and the host country's valuation of retaining the FDI (and therefore the best offer it would be prepared to make in order to retain the FDI). This is compared to the right-hand side, the best bid that country $A$ would be prepared to make less the cost of relocating production to that country. ${ }^{16}$ When condition (3) holds, then country $B$ 's geographic advantage together with the value to $B$ of the FDI exceeds the gain that the MNE would get from moving to country $A$, even if $A$ offered a subsidy to the firm equal to its entire national welfare benefit from the FDI. In the bidding equilibrium, country $A$ will offer $w_{A 2}$, while country $B$ will trump this with a tax of just less than:

$$
\tau_{B}^{R} \equiv \Pi_{2}-\left(w_{A 2}-F\right),
$$

where the superscript $R$ stands for "retain". Essentially, $B$ can extract some of its geographic advantage, $\Pi_{2}$, through its tax, but this is tempered by having to offset the size of $A$ 's bid, $w_{A 2}$. $B$ 's equilibrium tax is increasing in $F$ because a higher relocation cost creates a greater impediment to relocation.

Now suppose that country $A$ won the plant in period 1 . Country $B$ will then face a moredemanding condition in order to host production in period 2, winning the plant in period 2 if and only if:

$$
w_{B 2}+\Pi_{2}-F>W_{A 2}
$$

Condition (5) can be interpreted in an analogous manner to (3). Country $B$ can capture the plant from $A$ in period 2 because it is willing and able to offer the MNE a higher level of after-tax profits. In these circumstances, $A$ 's losing subsidy offer is $W_{A 2}$ while $B$ will attract the FDI with a winning tax of:

$$
\tau_{B}^{C} \equiv \Pi_{2}-\left(W_{A 2}+F\right)
$$

\footnotetext{
16 To recap, we assume that a country never makes an offer to the firm that exceeds the national welfare benefit of attracting the FDI.
} 
where the superscript $C$ stands for "capture". Country B's equilibrium tax when capturing the MNE is its period-2 geographic advantage, $\Pi_{2}$, less the sum of $A$ 's best offer and the cost of relocating the FDI to $B$.

If conditions (3) and (5) both hold, then $B$ wins the plant in period 2, regardless of the winner in period 1 . While the location of the FDI in period 2 is the same in both cases, the tax that country $B$ can charge in period 2 depends on the firm's location in period 1 . To see this, subtract (6) from (4) to find the tax difference,

$$
T_{B} \equiv \tau_{B}^{R}-\tau_{B}^{C}=\left(W_{A 2}-w_{A 2}\right)+2 F>0 .
$$

Country $B$ can charge a higher tax in period 2 if it retains the FDI, as opposed to capturing it from country $A$. This occurs because the sunk cost creates a disincentive to relocate that can be exploited by an existing host and requires compensation from a potential new host. This is compounded by $\left(W_{A 2}-w_{A 2}\right)>0$, which reflects the fact that country $A$ is prepared to make a stronger bid in order to retain existing production, as opposed to the best offer it would make to capture new FDI in period 2.

\subsection{BB equilibrium in period 1}

For $B B$ to be the equilibrium under tax competition, there are two (mutually exclusive and exhaustive) cases to consider for the period-1 competition. We consider first the case where the MNE always locates in $B$ in period 2, regardless of its location in period 1, such that the location profile will be either $A B$ or $B B$.

Country $B$ wins the plant in period 1 if and only if it is prepared to offer the MNE a higher PDV of after-tax profits than is offered by country $A$. The benefit to country $B$ from hosting the FDI in both periods 1 and 2 (as opposed to only attracting the FDI in period 2) is the sum of its valuation of the FDI in period 1, together with the discounted future benefit of retaining the FDI and the associated increase in tax that it can levy in equilibrium. This can be written as: 


$$
\Omega_{B}+\delta T_{B}, \text { where } \Omega_{B} \equiv W_{B 1}+\delta\left(H_{B 2}-h_{B 2}\right) .
$$

Similarly, the value to country $A$ of attracting the FDI in period 1 will reflect the instantaneous benefit that it gains from hosting the FDI, together with the discounted impact of subsequently losing the FDI in period 2:

$$
\Omega_{A} \equiv W_{A 1}+\delta\left(m_{A 2}-M_{A 2}\right)
$$

$\Omega_{A}$ and $\Omega_{B}$ therefore represent the largest subsidies that countries $A$ and $B$, respectively, would be willing to offer in period 1 , when it is known that production will take place in country $B$ in period 2.

In period 1 , the firm faces a choice between locating in country $B$ and remaining there or it can invest in country $A$ initially and move to $B$ in period 2 . This choice will be influenced by $\Pi_{1}$, the geographic advantage of locating in country $B$ in period 1 , and the future cost of relocation, $\delta F$, taking into account that its future tax burden will fall by $T_{B}$ if it decides to relocate.

Combining the benefits to the firm and country $B$ of continued production in $B$ over the two periods with country $A$ 's gains from period 1 production, it is clear that location profile $B B$ will arise if and only if the following condition is satisfied:

$$
\Omega_{B}+\left(\Pi_{1}+\delta F\right)>\Omega_{A} .
$$

The tax terms have disappeared from condition (7). This arises because the best offers that the countries are willing to make in period 1 rise with expected future tax revenue, meaning that expected, future tax payments are effectively rebated to the MNE through the subsidy that it is offered in period 1 . We examine the welfare significance of (7) below.

In isolating the conditions for $B B$ to be the MNE's equilibrium location profile, the second case that we must consider is the tax competition in period 1 that occurs when condition (3) holds but condition (5) fails. In this case, the winner of the FDI in period 1 retains it in period 2, so the MNE's location profile is either $A A$ or $B B$. Once again, the winner of the 
period 1 tax competition will be the country that is willing to offer the MNE the higher PDV of after-tax profits.

For each country, its period-1 valuation of the FDI now must reflect the fact that it is aware that the MNE will not relocate between periods. Consequently, winning the FDI in period 1 has repercussions for period 2 in that it guarantees that production does not move away. Thus the benefit to country $i$ from attracting the FDI in period 1 is the sum of its valuation of the FDI in period 1, together with the discounted future benefit of remaining host to the FDI and the associated tax that it can levy in equilibrium. This can be written as:

$$
\Theta_{i}+\delta \tau_{i}^{R}, \quad \text { where } \quad \Theta_{i} \equiv W_{i 1}+\delta\left(H_{i 2}-M_{i 2}\right)
$$

By analogy with country $B$ 's tax, defined in equation (4), country $A$ 's equilibrium tax to retain the FDI will be:

$$
\tau_{A}^{R} \equiv-\Pi_{2}-\left(w_{B 2}-F\right),
$$

From the point of view of the firm, it now faces a location choice in period 1 where it knows that it will remain in its initial location in period 2 . This choice will be influenced by the PDV of geographic advantage over the two periods $\left(\Pi_{1}+\delta \Pi_{2}\right)$, and by a comparison of the future tax levels charged by each of its potential hosts in period 2 .

Combining the benefits to the firm and country $B$ of continued production in $B$ over the two periods with country $A$ 's gains from production in both periods, it is clear that location profile $B B$ will arise if and only if the following condition is satisfied:

$$
\Theta_{B}+\left(\Pi_{1}+\delta \Pi_{2}\right)>\Theta_{A}
$$

Once again, and for the same reasons as above, the tax terms wash out from condition (9).

\subsection{BB as the equilibrium under tax competition}

Before turning to efficiency considerations, it is useful to summarise the conditions that we have isolated for $B B$ to be the tax-competition equilibrium. This requires condition (3) and one 
of conditions (7) and (9) to hold. Condition (3) must hold because it ensures that country $B$ retains the FDI in period 2 if it had previously won the FDI in period 1 . In addition, where condition (5) holds, such that country $B$ would capture the FDI from country $A$ in period 2, country $B$ wins the FDI in period 1 if condition (7) holds. Alternatively, where condition (5) fails, such that country $A$ would retain in period 2 the FDI that it won in period 1, country $B$ wins the FDI in period 1 if condition (9) holds.

\subsection{Efficiency}

Efficiency is achieved when the PDV of global welfare is maximised. The PDV of global welfare varies with the MNE's location profile and thus takes one of four possible values:

$$
\begin{aligned}
& G_{A A} \equiv H_{A 1}+M_{B 1}+\pi_{A 1}-F+\delta\left(H_{A 2}+M_{B 2}+\pi_{A 2}\right) ; \\
& G_{A B} \equiv H_{A 1}+M_{B 1}+\pi_{A 1}-F+\delta\left(m_{A 2}+h_{B 2}+\pi_{B 2}-F\right) ; \\
& G_{B A} \equiv M_{A 1}+H_{B 1}+\pi_{B 1}-F+\delta\left(h_{A 2}+m_{B 2}+\pi_{A 2}-F\right) ; \\
& G_{B B} \equiv M_{A 1}+H_{B 1}+\pi_{B 1}-F+\delta\left(M_{A 2}+H_{B 2}+\pi_{B 2}\right) .
\end{aligned}
$$

Taxes do not appear in the global welfare expressions because they simply redistribute income between the host country and the owners of the firm.

We shall now establish a central result of our paper.

Proposition 2. The MNE's equilibrium location profile under tax competition is always efficient.

Proof. We prove this by showing that the conditions for $B B$ to be the equilibrium under tax competition are equivalent to those for $B B$ to be efficient. The equivalence of the equilibrium and efficiency conditions for each of the other possible location profiles of $A A, A B$ and $B A$ is straightforward to demonstrate using analogous arguments.

For $B B$ to be efficient, we require $G_{B B}>G_{B A}$. It is straightforward to show that this is equivalent to condition (3). In addition, we require 


$$
G_{B B}>\max \left\{G_{A A}, G_{A B}\right\}
$$

Condition (5) is equivalent to $G_{A B}>G_{A A}$. If it holds, then the efficiency of $B B$ requires $G_{B B}>G_{A B}$, which is equivalent to condition (7). Alternatively, if $G_{A A}>G_{A B}$ such that condition (5) fails, then the efficiency of $B B$ requires $G_{B B}>G_{A A}$, which is equivalent to condition (9).

It should now be clear that the conditions for $B B$ to be the $\mathrm{TC}$ equilibrium are equivalent to those making $B B$ the efficient location profile. Thus, $B B$ arises as the equilibrium under tax competition if and only if it is efficient. This completes our proof of Proposition 2. (To repeat, it is straightforward to show that the equilibrium and efficiency conditions also coincide for the other three possible location profiles, $A A, A B$ and $B A$.)

We have thus established that the outcome of tax competition is as if a benevolent social planner had chosen the location profile of FDI to maximise discounted world welfare. Technically, this is an extremely useful result because it enables us to short-circuit the cumbersome, period-by-period mechanics of solving the tax-competition game. Instead, in order to derive the location profile under tax competition, we simply need to solve for the efficient location profile. We shall make use of this procedure in our example in section 5, below.

The fact that international competition for FDI leads the MNE to choose the efficient location profile in equilibrium is quite intuitive. The equilibrium is efficient because tax competition internalises the welfare externalities from inward FDI (on workers, indigenous firms, consumers, etc. in the host countries). In contrast, under laissez faire the MNE chooses its plant location solely on the basis of its pre-tax profits, overlooking the externalities of its FDI decision on welfare. 
To illustrate the possibilities of inefficiency under laissez faire, we now adopt a more structured set-up where the two countries are identical in all respects apart from their population size.

\section{Asymmetric regional growth: an example}

We now put some more structure on our modelling framework, in order to address the question as to whether firms become more footloose in the face of international tax competition to attract FDI. Specifically, we must tie down how the shift in geographic advantage between nations affects both the profits of the firm and the welfare of the countries as the firm makes its location choice in each period.

We therefore assume that geographic advantage adjusts in response to changes in the relative size of the competing nations. Let the population of country $B$ change from one period to the next, while that of country $A$ remains the same. We normalise the population of $A$ to one and let $n_{t}$ denote the size of country $B$ in period $t$. We define $v_{t} \equiv n_{t}-1$ to be $B$ 's "size advantage" in period $t$, acknowledging that $v_{t}$ may be positive or negative. ${ }^{17}$ The size of $B$ might change for a variety of demographic, economic or border-related reasons such as population growth, emigration, immigration, real income growth, territorial expansion, etc. ${ }^{18}$

Let $h$ and $m$ denote the per-capita levels of welfare in a country resulting from it hosting the FDI and importing the good, respectively. Thus, the per-capita welfare gain from local production is $w \equiv h-m$, where we assume that this is strictly positive, $w>0 .{ }^{19}$ Local production therefore offers an aggregate welfare gain to the host country equal to $w$ for $A$ in each period and $n_{t} w$ for $B$ in period $t$. These benefits, which are common knowledge, form the

\footnotetext{
17 ' 's size advantage is therefore given by $-v_{\mathrm{t}}$. At this stage, we do not intend our usage of the term "advantage" in the definition of $v_{t}$ to carry any welfare connotations. It is a purely a descriptive label.

18 There are several real-world examples of discrete changes in market size, such as the unification of Germany and the eastern enlargement of the EU.

19 For ease of exposition, we drop the assumption that a country is worse off after losing production compared to never having hosted the FDI such that $W_{i 2} \equiv w_{i 2}$.
} 
central motivation for the countries' willingness to bid for inward FDI. We define $W_{t} \equiv w v_{t}$ as $B$ 's "welfare advantage" in period $t$, a measure of the additional benefit that country $B$ derives from inward FDI as compared to the gains accruing to country $A$ from attracting the FDI.

The firm earns per-capita variable profits of $\pi_{L}$ on local sales and $\pi_{F}$ on foreign (export) sales. The profit premium on local sales is $\omega \equiv \pi_{L}-\pi_{F}$, where $\omega>0$ as a result of the intraregional trade cost. Consequently, the firm's total variable profits in period $t$ are $\pi_{L}+n_{t} \pi_{F}$ if production is located in $A$ while they are $\pi_{F}+n_{t} \pi_{L}$ if production is located in $B$. In this setting, $B$ 's "geographic advantage" in period $t$ is $\Pi_{t}=\omega v_{t}{ }^{20}$

\subsection{Are firms more footloose under tax competition?}

The impact of tax competition on the location choice of the firm in each of the two periods forms our central result, which we present as a further proposition.

\section{Proposition 3.}

(i) When countries compete to attract FDI, a forward-looking firm will only choose to switch the location of its production between periods 1 and 2 if the smaller country in the first period becomes the larger country in the second, as is also the case for relocation under laissez faire.

(ii) For such a relocation to occur, the size advantage needed by the winning country is lower in both periods under tax competition than under laissez faire.

Part (i) of Proposition 3 highlights qualitative similarities between equilibrium relocation under laissez faire and tax competition. In both cases, a reversal in the relative size of the two countries is necessary for relocation to occur in equilibrium. Any such relocation will result in the firm producing in the larger country in each period. However, a reversal is not sufficient

\footnotetext{
${ }^{20}$ In this simple structure, both geographic advantage and welfare advantage are being driven by the differences in the populations of the two countries
} 
for relocation to occur. There are parts of quadrants 2 and 4 in both Figures 1 and 3 where the firm chooses not to relocate its production.

\section{FigURE 3 ABOUT HERE}

Part (ii) of Proposition 3 answers the question posed in the title of our paper. Loosely stated, it says that there should be greater observed plant mobility in equilibrium between periods 1 and 2 under tax competition compared to that under laissez faire. Under our particular parameterisation of the model in this example, we can use Figure 3 to make this comparison.

In the previous section, we determined that if country $A$ won the plant in period 1 , country $B$ had to overcome condition (5) in order to host production in period 2. Substituting the specific notation for our example, this condition can be rewritten as

$$
\Pi_{2}>\lambda F, \text { where } \lambda \equiv \frac{\omega}{w+\omega}<1 .
$$

The TC thresholds for tax competition are shown as solid lines in Figure 3 to distinguish them from the dashed, LF lines for laissez faire. In the second quadrant of Figure 3, this horizontal threshold under TC is lower than the corresponding threshold under LF. The other TC thresholds also shift in a similar fashion. What is obvious is that there are now parameter configurations that will result in a relocation of production under tax competition when it would not have occurred under laissez faire.

Given that the firm will subsequently leave, why is the size advantage required to win its production in period 1 lower under tax competition than under laissez faire? Consider, for example, the condition for country $A$ to win the FDI in period 1 under tax competition when $v_{2}$ is sufficiently large such that $\Pi_{2}>\lambda F$ and therefore the firm's period-2 location is always $B$. In period 1, the firm can anticipate perfectly the taxes that it will pay in $B$ in period 2 . Therefore, for given national offers in period 1, the difference in the firm's discounted after-tax profits 
from choosing $A$ over $B$ in that period is $\delta T_{B}-\Pi_{1}-\delta F$, where $T_{B}$ was defined above and is strictly positive. $^{21}$

Effectively, the firm can strategically manipulate its tax burden in period 2 through its choice of location in period 1. It is aware that, by choosing $A$ in period 1 , it will reduce its tax burden in $B$ in period 2 compared to what it would have had to pay had it chosen $B$ as its initial location. Put alternatively, with endogenously determined fiscal inducements, the government of $B$ absorbs some of the firm's relocation cost in its period-2 tax/subsidy offers. Under laissez faire, the firm cannot avail itself of this opportunity and, consequently, the firm is more willing to relocate under tax competition than it would be otherwise.

\section{Extensions to the analysis}

We now briefly discuss the implications of two of our modelling assumptions: commitment (or the lack of it); and having only two periods. In order to make our results more concrete, we continue to use the structure from our example in Section 5, above.

\subsection{Commitment}

Consider what would happen if we assumed binding commitments in both tax/subsidy-setting and location choice. ${ }^{22}$ Suppose that, at the beginning of period 1, the firm commits to remain in whichever country it initially chooses, and each country commits, in present-value terms, to a lifetime tax/subsidy total, even though it would be in the winning country's interests to change this after the firm has incurred its sunk investment cost. We are assuming that all commitments are credible.

Essentially, the assumption of binding commitments returns our two-period analysis of competition to a simpler, one-shot case. The valuations of countries $A$ and $B$ are $(1+\delta) w$ and

\footnotetext{
${ }^{21}$ By choosing $A$ over $B$ in period 1, the firm enjoys $A$ 's period-1 geographic advantage of $-\Pi_{1}$, but it has to build a second plant (in $B$ ) in period 2 costing $-\delta F$. In the absence of taxes, the firm therefore prefers $A$ to $B$ in period 1 if $\Pi_{1}<-\delta F$, the vertical $A B / B B$ boundary in Figure 1.

${ }^{22}$ Our definition of "commitment" follows King and Welling (1992, p. 65).
} 
$\left(n_{1}+\delta n_{2}\right) w$, respectively. The PDV of the firm's pre-tax profits is $(1+\delta) \pi_{L}+\left(n_{1}+\delta n_{2}\right) \pi_{F}-F$ in $A$ and $(1+\delta) \pi_{F}+\left(n_{1}+\delta n_{2}\right) \pi_{L}-F$ in $B$. Maintaining our assumption that $w+\omega>0$, it follows that $B$ wins the firm for both periods if and only if $\delta v_{2}>-v_{1}$. Therefore, given that $\Pi_{t}=\omega v_{t}$, the boundary between $A$ 's winning region and that of $B$ with binding commitments is given by the downward-sloping, inter-regional boundary between $A A$ and $B B$ in Figures 1 and $3 .^{23}$

\subsection{More periods}

How limiting is our assumption of having two periods? With only two periods, relocation either coincides with the change in economic geography or the firm does not move. If we had more periods, then a richer sequencing of moves would be possible.

We can extend the analysis to a multi-period, infinite horizon model in which $B$ 's geographic advantage builds over time. In such a setting, under laissez faire the firm decides not only whether it should relocate production to $B$, presuming that it is initially operating in $A$, but also when this should occur. The firm has an incentive to delay its new FDI as late as possible, in order to put off the outlay of $F$, but this incentive is tempered by the competing attraction of moving to the larger market.

Suppose that we consider an environment where the firm is initially based in $A$, but this country's growth is outpaced by that of rival $B$. Thus at the starting point of our multi-period analysis, $B$ now has the larger market $\left(v_{0} \geq 0\right)$ and this geographic advantage will continue to grow over time. The firm will choose to relocate its production to $B$ at some point in time, with or without government incentives. However, we wish to determine whether this jump takes place earlier or later under tax competition as compared to laissez faire.

\footnotetext{
23 Note that because the no-commitment equilibrium under tax competition is efficient, there will be scope for welfare-enhancing renegotiations whenever the binding-commitment and no-commitment equilibria diverge (i.e. whenever the latter involves relocation between periods).
} 
Under laissez faire, the firm will seek to maximise the PDV of its stream of profits by choosing the time $s_{\mathrm{LF}}$ at which it should relocate its production from $A$ to $B$. Dropping constant terms, this is equivalent to the firm comparing the PDV of its stream of geographic advantage once it relocates, offset by the discounted cost of its new FDI:

$$
\max _{s_{\mathrm{LF}}}\left\{\sum_{t=s_{\mathrm{LF}}}^{\infty} \delta^{t} \Pi_{t}-\delta^{s_{\mathrm{LF}}} F\right\} .
$$

Expression (11) balances the benefits to the firm of moving to the larger country early in order to take advantage of the higher profits resulting from producing in its larger market, against deferring the cost of investing in a new plant as long as possible.

The outcome under tax competition is more complex. The equilibrium offers once the firm has relocated to $B$ are straightforward to calculate but the national offers prior to the move are harder to work out, as they will depend upon expectations as to when the firm will move. Rather than make these calculations, we take advantage of our equivalence result (Proposition 2) in the 2-period case that the efficient location choice coincides with the outcome under tax competition. We conjecture that the tax-competition outcome will continue to be more efficient than that under laissez faire when the analysis is extended to a longer time horizon. Thus, we can infer from the timing of the welfare-maximising relocation whether international competition to attract FDI accelerates relocation or retards it.

The best time for relocation to occur with respect to overall welfare is $s_{W}$, where $s_{W}$ maximises the following expression:

$$
\max _{s_{W}}\left\{\frac{1}{\lambda} \sum_{t=s_{W}}^{\infty} \delta^{t} \Pi_{t}-\delta^{s_{W}} F\right\} .
$$

Clearly, given that $1 / \lambda>1$, more weight is now placed upon the period after the jump in expression (12) compared to expression (11), such that $s_{W}<s_{\text {LFF }}$ Thus relocation occurs earlier under tax competition than under laissez faire. Moreover, even if tax competition does not 
generate a fully welfare-maximising outcome, our presumption that it is more efficient than laissez faire means that the relocation time under tax competition will be earlier than that under laissez faire $\left(s_{\mathrm{TC}}<s_{\mathrm{LF}}\right)$.

\section{Conclusions}

It is a well-established result that the tax burden tends to be higher on immobile factors of production than on relatively "footloose" factors. For example, new inward investment typically receives more favourable tax treatment than sunk FDI. The MNE in King et al. (1992, 1993) responds to this fact by trading its anticipated future tax payments to its host government for initial subsidies from that government while its FDI is still mobile. Our paper complements King et al. by focussing on how the MNE strategically responds to the differential tax treatment of new versus established investment through its international relocation decision.

Our modelling framework contains geographical change over time, giving governments the opportunity to bid in each period to attract or retain the MNE's FDI. Our central result is that international competition for FDI can result in more efficient location choices. In the context of a specific example, tax competition may lead to more industrial relocation than in the absence of government intervention. This outcome appears to be consistent with popular and media arguments (e.g. Financial Times, 2010) that the availability of public subsidies facilitates international plant relocation. However, from an efficiency point of view, our analysis should not be taken to imply that there is excessive plant mobility under tax competition, but rather that there can be too little plant mobility under laissez faire. The legitimate, popular concerns about international subsidy competitions for large FDI projects should therefore be more properly interpreted as concerns about income distribution, rather than efficiency. 


\section{References}

Besley, Timothy, and Paul Seabright (1999), "The effects and policy implications of state aids to industry: an economic analysis.” Economic Policy, 14, 13-53.

Bjorvatn, Kjetil, and Carsten Eckel (2006), "Policy competition for foreign direct investment between asymmetric countries." European Economic Review, 50, 1891-1907.

Black, Dan A., and William H. Hoyt (1989). "Bidding for firms.” American Economic Review, 79(5), 1249-1256.

Ferrett, Ben, and Ian Wooton (2010a), "Competing for a duopoly: international trade and tax competition." Canadian Journal of Economics, 43(3), 776-794.

Ferrett, Ben, and Ian Wooton (2010b), "Tax competition and the international distribution of ownership: an invariance result." International Tax and Public Finance, 17(5), 518531.

Financial Times (2010), "Questions surround EU relocations," 1 December, available at http://www.ft.com/cms/s/0/74ab02a6-fd85-11df-a049-

$\underline{00144 \mathrm{feab} 49 \mathrm{a} \cdot \mathrm{htm} l \text { ?siteedition=uk\#axzz48oi3kEfr. }}$

Fumagalli, Chiara (2003), "On the welfare effects of competition for foreign direct investments." European Economic Review, 47, 963-983.

Furosawa, Taiji, Kazumi Hori and Ian Wooton (2015), “A race beyond the bottom: the nature of bidding for a firm.” International Tax and Public Finance, 22(3), 452-475.

Haaland, Jan I., Ian Wooton and Giulia Faggio (2003), "Multinational firms: easy come, easy go?” FinanzArchiv, 59, 3-26.

Haaparanta, Pertti (1996), "Competition for foreign direct investments." Journal of Public Economics, 63, 141-153. 
Haufler, Andreas, and Ian Wooton (1999), "Country size and tax competition for foreign direct investment.” Journal of Public Economics 71, 121-139.

Janeba, Eckhard (1998), "Tax competition in imperfectly competitive markets.” Journal of International Economics, 44(1), 135-153.

King, Ian, and Linda Welling (1992), "Commitment, efficiency and footloose firms." Economica, 59, 63-73.

King, Ian, R. Preston McAfee and Linda Welling (1993), "Industrial blackmail: dynamic tax competition and public investment." Canadian Journal of Economics, 26, 590-608.

Konrad, Kai A., and Dan Kovenock (2009), “Competition for FDI with vintage investment and agglomeration advantages." Journal of International Economics, 79, 230-237.

Olsen, Trond E., and Petter Osmundsen (2003), "Spillovers and international competition for investments." Journal of International Economics, 59, 211-238. 


\begin{tabular}{|c|c|c|}
\hline & \multicolumn{2}{|c|}{ Investment Environment } \\
\hline & Laissez faire & Tax competition \\
\hline \multirow{4}{*}{ Period 1} & \multirow{3}{*}{$\begin{array}{l}\text { Firm chooses its location, } \\
\text { invests, produces and sells. }\end{array}$} & $\begin{array}{l}A \text { and } B \text { announce offers to } \\
\text { attract the FDI. }\end{array}$ \\
\hline & & $\begin{array}{l}\text { Firm chooses its location, } \\
\text { invests, produces and sells. }\end{array}$ \\
\hline & & $\begin{array}{l}\text { Tax/subsidy paid to/by the } \\
\text { winning country. }\end{array}$ \\
\hline & \multicolumn{2}{|c|}{ Geographic advantage may change. } \\
\hline \multirow{3}{*}{ Period 2} & \multirow{3}{*}{$\begin{array}{l}\text { Firm chooses whether to } \\
\text { relocate, produces and sells. }\end{array}$} & $\begin{array}{l}A \text { and } B \text { announce revised } \\
\text { offers to attract/retain the FDI. }\end{array}$ \\
\hline & & $\begin{array}{l}\text { Firm chooses whether to } \\
\text { relocate, produces and sells. }\end{array}$ \\
\hline & & $\begin{array}{l}\text { Tax/subsidy paid to/by the } \\
\text { winning country. }\end{array}$ \\
\hline
\end{tabular}

Table 1. Sequence of moves

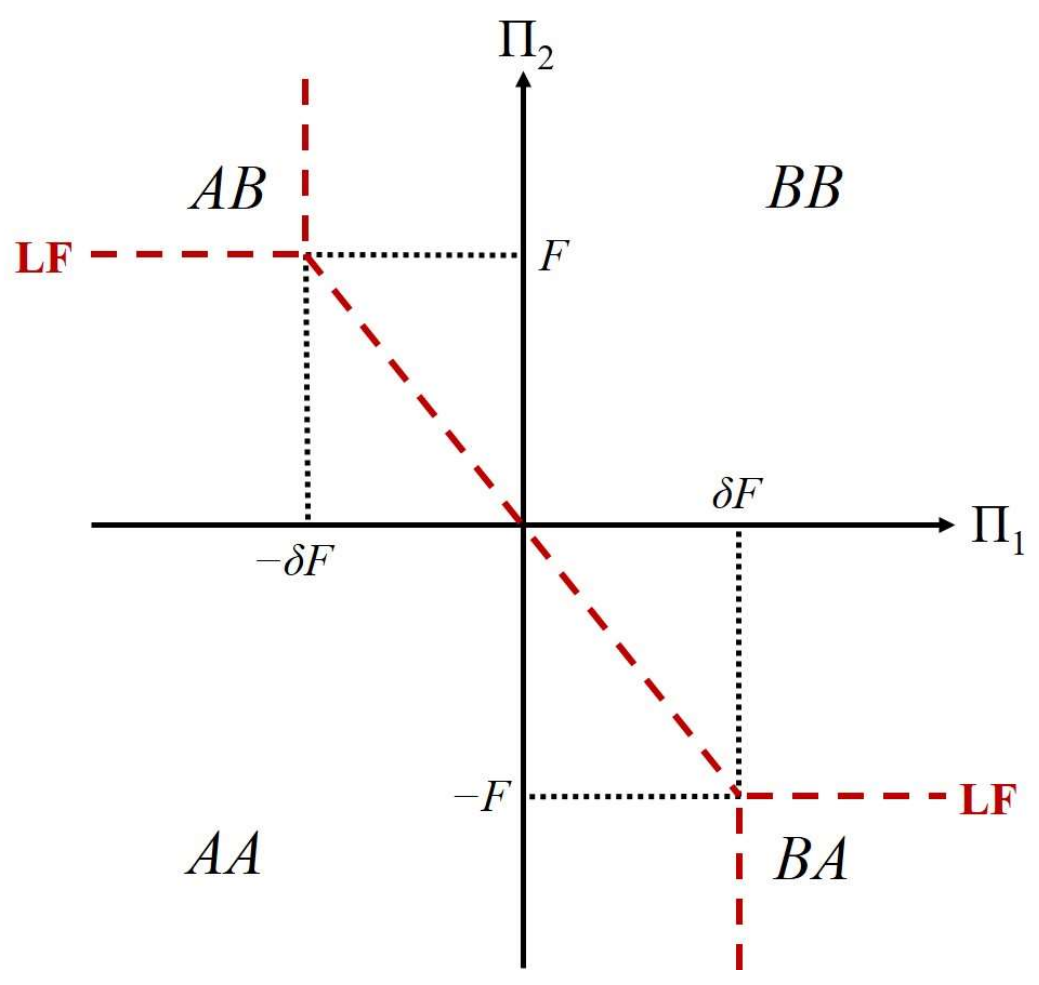

Figure 1. Equilibrium location profiles under laissez faire 


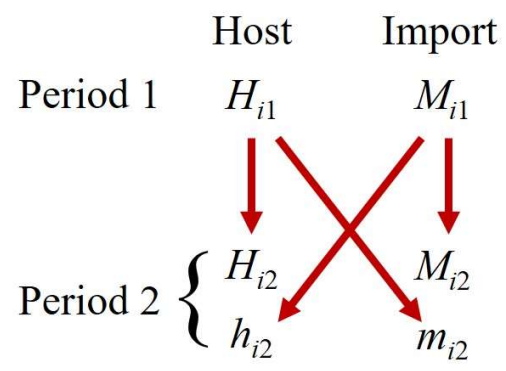

Figure 2. National welfare levels

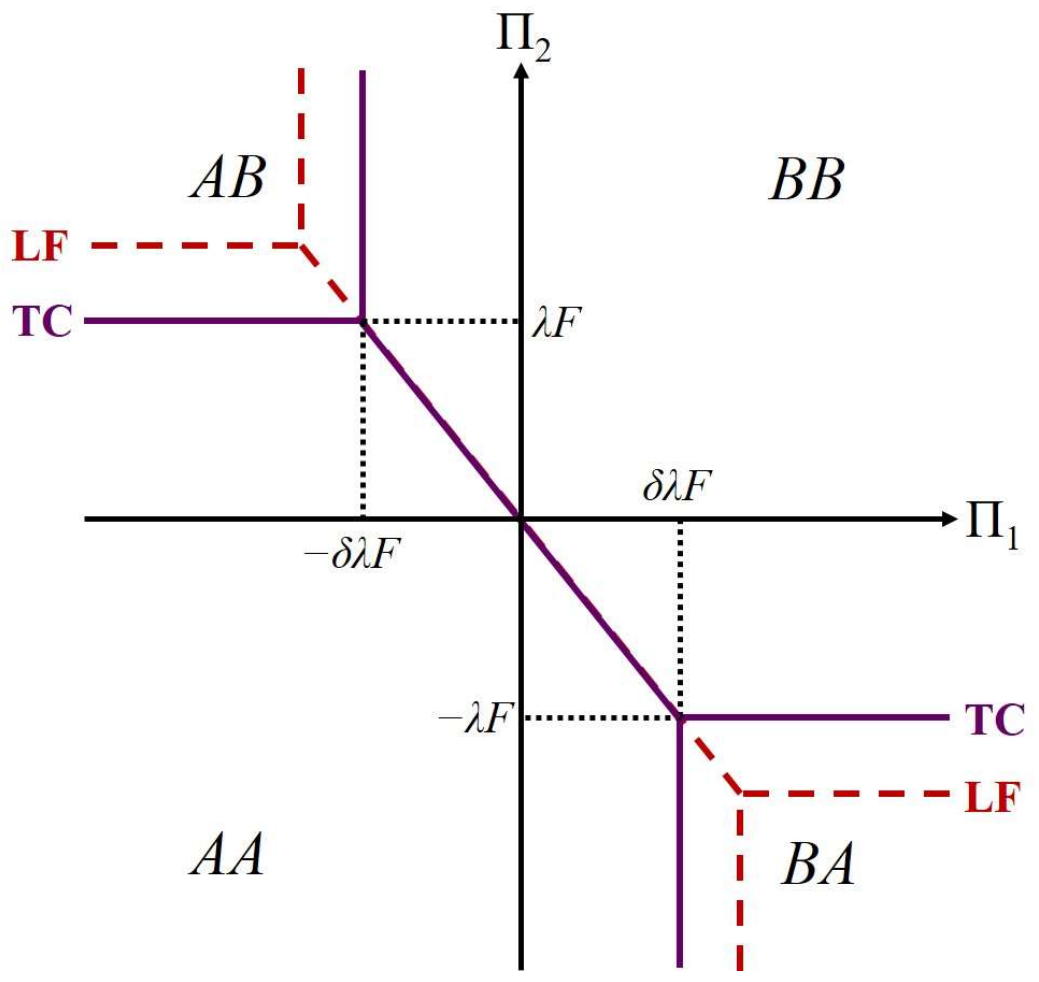

Figure 3. Change in location profiles resulting from tax competition 